\section{Innovative Learning Spaces That Promote Undergraduate Research}

\section{doi: $10.18833 /$ spur/1/2/7}

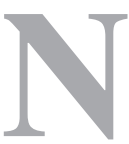

ew approaches and designs for learning spaces on college campuses that are intended to encourage group work, facilitate active learning pedagogies, and promote a "making" culture also provide great environments for undergraduate research. These newly designed spaces are found in libraries, residence halls, and student unions, in addition to renovated classrooms and academic buildings. This issue of Scholarship and Practice of Undergraduate Research explores how campuses have designed and utilized these new and repurposed spaces to increase opportunities for undergraduate research and scholarship.

Jeanne L. Narum (Learning Spaces Collaboratory), Kimberley Frederick (Skidmore College), and Michael A. Palladino (Monmouth University) describe the development of a national effort to support educational innovation at primarily undergraduate institutions with the aim of increasing students' aspirations for careers in research. One element of that work was a framework for the development of innovative learning spaces for student research, begun under the umbrella of Project Kaleidoscope. Member campuses pursued related initiatives and ultimately formed the Learning Spaces Collaboratory to continue the focus on improving physical environments through learner-centered planning. Their article in the journal's theory section describes the intentional planning and design framework developed in this collaborative effort and presents examples of projects at Monmouth University and Skidmore College.

Mary Beth Hawkins, Miriam Ferzli, and Lisa Paciulli (North Carolina State University) chose to emulate a studio approach-more typical of creative disciplines - for student learning in biology by setting up a modified studio environment for their classes. Students operate on flexible schedules, moving between a laboratory and adjoining conference room space shared with peers and mentors. Assessment data show significant gains by participants in this course-based research experience. This article, which may be found in the assessment section, includes both practice and a thoughtful project assessment.

Campus libraries are keen to ensure that students continue to benefit from research resources they provide, as well as to stay current with innovative pedagogies that include group learning and new technologies. Kathleen Baril and Kelly Kobiela (Ohio Northern University) share their experiences with reimagining the library in ways that enhance the undergraduate research experience in their practice article.

When their university sought to develop new activelearning classrooms, project leaders Kimberly K. Eby and Laura A. Lukes (George Mason University) approached the opportunity as a way to engage faculty in the design process. This practice-focused article describes how the Learning Environments Group employed a data-driven, iterative design process to create spaces that support the integration of inquiry-driven activities in courses. Faculty learning communities established through the process continue to encourage innovative use of the active learning classrooms and offer peer support for instructors new to this type of teaching.

Two of this issue's vignettes expand the examples of how technologically innovative learning spaces enhance undergraduate research. Dawson and coauthors (University of North Georgia) adapted an augmented reality sandbox so that students in cognitive sciences could explore models of brain transitions via "playing" with dynamic topographical maps. In another short piece, Loretta Ebert (Siena College) describes the construction of a Digital Scholarship Center that promotes undergraduate research in a variety of disciplines, including communication and humanities.

The students of Thomas B. Higgins (Harold Washington College) benefited from the development of active-learning chemistry laboratories at nearby Truman College in a different way. They claimed the abandoned space in the "old" chemistry lab for the construction of an interdisciplinary, collaborative maker-space to support a new undergraduate research program building high-altitude balloon payloads with student teams.

Elizabeth Roberts-Kirchoff, Shuvra Das, and Gary Kuleck describe newly developed spaces in the College of Engineering \& Science at the University of Detroit Mercy that are committed to providing authentic research experiences in two disparate topic areas, both of which are critical to research and development opportunities in Detroit. The Center for Automotive Systems Engineering Education and the Innovative Space for Research and Exploration in biomedical sciences together significantly expand students' access to transformational research opportunities. 
Other articles in the issue feature topics of perpetual interest to the undergraduate research community. Evan D. Bradley (Pennsylvania State University-Brandywine), Michelle Bata (Clark University), Heather M. Fitz Gibbon (College of Wooster), Caroline J. Ketcham (Elon University), Brittany A. Nicholson (College of Wooster), and Meagen Pollock (College of Wooster) analyze the structures and prevalence of multi-mentoring teams by surveying undergraduate researchers across their four institutions. The authors also explore the types of support provided by the mentors as well as disciplinary differences, and their study finds higher rates of both mentorship and multi-mentoring in the natural sciences. Annemarie Nicols-Grinenko and colleagues discuss strategies for building a culture for undergraduate research at Hunter College, City University of New York. Using Linear Discriminant Analysis (LDA), M. Gordon Byrd and Zhixin Kang examine funding decisions for an undergraduate research scholarship by a council at the University of North Carolina at Pembroke.

This issue demonstrates the critical role played by thoughtfully designed learning spaces and support mechanisms in enriching the campus culture of undergraduate research. Each example builds on the notion that collaboratively designed spaces that focus on the learner experience lead to successful outcomes. Facilities that leverage new technologies and pedagogies can significantly affect faculty members' ability to integrate research experiences into their courses and to provide access to transformative experiences for all of their students.

\section{Coming up in SPUR...}

Spring 2018:

"Undergraduate Research and

Student Success Outcomes"

\section{Summer 2018:}

"Leveraging Undergraduate Research to

Foster Diversity and Achieve Equity"

Fall 2018:

"Mentoring Models"

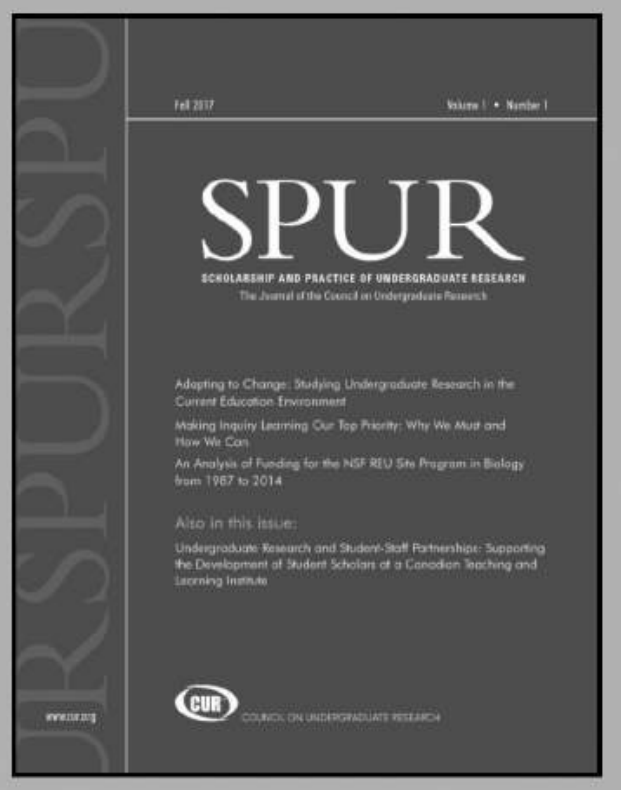

